\title{
Diagnostic and Prognostic Value of Survivin in Pleural Effusion
}

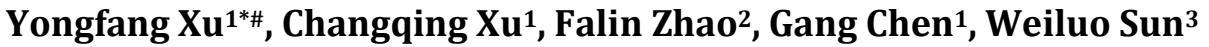 \\ ${ }^{1}$ Department of Respiratory Medicine, The Affiliated Hospital of Hangzhou Normal University, Hangzhou, China \\ ${ }^{2}$ Department of Public Health, Medical School of Hangzhou Normal University, Hangzhou, China \\ ${ }^{3}$ Department of Respiratory Medicine, The Third Hospital of Hangzhou, Hangzhou, China \\ Email: "yongfangxu116@163.com
}

How to cite this paper: $\mathrm{Xu}, \mathrm{Y} . F ., \mathrm{Xu}, \mathrm{C} . \mathrm{Q}$., Zhao, F.L., Chen, G. and Sun, W.L. (2018) Diagnostic and Prognostic Value of Survivin in Pleural Effusion. Advances in Lung Cancer, 7, 9-20.

https://doi.org/10.4236/alc.2018.72002

Received: July 10, 2018

Accepted: July 28, 2018

Published: July 31, 2018

Copyright (๑) 2018 by authors and Scientific Research Publishing Inc. This work is licensed under the Creative Commons Attribution International License (CC BY 4.0).

http://creativecommons.org/licenses/by/4.0/

\section{cc) (i) Open Access}

\begin{abstract}
Background: Survivin is an inhibitor of apoptosis that may be a novel diagnostic and prognostic marker of cancer. Our study is to investigate the diagnostic and prognostic value of survivin for pleural effusions. Methods: Sixty-five pleural effusion patients were enrolled prospectively. Pleural effusion samples were examined for survivin level by ELISA. Pleural effusions were divided into three groups: Group I, malignant pleural effusion (MPE) ( $\mathrm{n}=$ 36); Group II, tuberculous pleurisy (TPE) $(\mathrm{n}=18)$; and Group III, transudative pleural effusion $(n=11)$. The accuracy of diagnosis and the correlation between survivin level and survival in malignant pleural effusions (MPE) were analyzed. Results: Survivin level was $320.50 \pm 228.24 \mathrm{pg} / \mathrm{ml}$ in MPE, $328.35 \pm 146.79$ $\mathrm{pg} / \mathrm{ml}$ in TPE and $318.87 \pm 208.39 \mathrm{pg} / \mathrm{ml}$ in transudative pleural effusion respectively. ROC curves for MPE versus TPE were analyzed, area under the ROC curve was 0.419 , and for the cutoff value of $254.85 \mathrm{pg} / \mathrm{ml}$ sensitivity was $44.4 \%$ and specificity $55.6 \%$. Survivin had no discriminative power in differentiating exudative effusions of MPE from non-MPE ( $p=0.648)$. There was no correlation between survivin level and age, sex. However, statistically significant difference was found between primary lung carcinoma (238.66 \pm $48.19 \mathrm{pg} / \mathrm{ml})$ and extra-pulmonary metastatic carcinomas $(435.09 \pm 320.62$ $\mathrm{pg} / \mathrm{ml}$ ) according to survivin level $(\mathrm{p}=0.033)$. Survivin levels can distinguish patients who had poor prognosis (median survival 96 days) and those who had good prognosis (median survival 206 days) in MPE. Conclusion: survivin levels detected with ELISA had no discriminative power in differentiating exudative effusions included MPE and TPE. However, over-expression of survivin correlates with poor prognosis in cancer patients. Our results suggest that survivin may be a potential prognostic marker in MPE.
\end{abstract}




\section{Keywords}

Survivin, Pleural Effusion, Diagnosis, Prognosis

\section{Introduction}

Pleural effusions have a variety of etiologies, including malignancies, pneumonia, tuberculosis, pulmonary embolism, cardiac failure and cirrhosis. Differentiating between malignant pleural effusion (MPE) and non-MPE often has important therapeutic implications [1] [2]. Malignant pleural effusion (MPE) is a common and important cause of cancer-related mortality and morbidity [3] [4]. Prompt diagnosis using minimally invasive test is important because the median survival after diagnosis of MPE is only 4 - 9 months. The sensitivity of cytologic examination of pleural effusion is variable with limited sensitivity [5] [6].

The initial diagnostic approach includes thoracocentesis and cytological, histological and biochemical examinations. However, the sensitivity of these noninvasive techniques is unsatisfactory [7] [8] [9]. The sensitivity of conventional cytology for the detection of malignant cells in pleural effusion is insufficient, too [6]. Differentiating between malignant pleural effusion (MPE) and non-MPE often has important therapeutic implications.

Survivin is an inhibitor of programmed cell death; it mediates suppression of apoptosis by inhibition of the caspases 3 and 7, the terminal effectors in apoptotic protease cascades [10]. It is selectively up-regulated in many human tumors, where its over-expression correlates with poor outcome [11] [12] [13]. Nevertheless, survivin expression in pleural effusions of cancer patients is rarely reported. This study evaluated the diagnostic value of survivin levels in pleural effusions and explored the possible relationship between surviving levels and survival.

\section{Materials \& Methods}

\subsection{Study Design and Sample Selection}

Between March 2017 and September 2017, a total of 65 patients admitted to our clinic were included in the study. All patients were follow-up for a period of 9 months, with telephone follow-up at least once for every month. Patients' demographics and tumor characteristics are summarized in Table 1. This study has been approved by the ethical committee and was in accordance with the ethical standards of the Committee for Human Experimentation, with the Helsinki Declaration of 1975 (revised in Tokyo 2004) and the Committee on Publication Ethics guidelines. All patients consecutively diagnosed with MPE, tuberculous pleurisy (TPE) and transudative pleural effusion were included. All patients were diagnosed according to criteria cited below which was considered as a reasonable standard for diagnosis. Medical history was taken from all patients included in the study. Physical examination was made, and poster-anterior 
Table 1. Distribution of patients according to primary etiology.

\begin{tabular}{ccc}
\hline N (\%) & & Survivin $(\mathrm{pg} / \mathrm{ml})$ \\
\hline Malignant pleural effusion & 36 & $320.50 \pm 228.24$ \\
Primary lung carcinoma & 21 & $238.66 \pm 48.19$ \\
Adeno & 14 & \\
Squamous & 6 & \\
Small cell carcinoma & 1 & $435.09 \pm 320.62$ \\
Metastatic other than lung & 15 & \\
Pancreas & 1 & \\
Esophagus & 2 & \\
Colon & 4 & $328.35 \pm 146.79$ \\
Gastrointestinal system & 6 & $318.87 \pm 208.39$ \\
Cervix & 1 & \\
Bladder & 1 & \\
Tuberculosis (TPE) & 18 & \\
Transudative pleural effusion & 11 & \\
\hline
\end{tabular}

No statistically significant difference was found between the three groups according to survivin level ( $\mathrm{p}=$ $0.989)$.

chest X-ray ordered. Patients with pleural effusion routinely underwent diagnostic thoracocentesis to obtain pleural fluid specimens for cell count; the measurement of total protein, lactate dehydrogenase (LDH) and cytological examination were checked. In addition, acid-fast bacilli were analyzed in effusions in the microbiology laboratory.

The diagnosis of TPE was done according to the following criteria; 1) Pathological demonstration of a necrotizing granulomatous inflammation in the pleural tissue sample taken with closed biopsy or Video Assisted Thoracoscopic Surgery (VATS); or 2) microbiologic isolation of mycobacterium tuberculosis in the pleural fluid; or 3) the routine examination of pleural fluid indicates lymphocyte-based exudates effusions with significant increase in adenosine deaminase ( $>40 \mathrm{U} / \mathrm{L}$ ); plus exclusion of other possible diagnosis by clinical and radiological examination. The diagnosis of MPE was done according to the following criteria; malignant cells in the cytology of the pleural fluid and/or on histopathologic examination of the pleural tissue obtained by VATS or pleural blind biopsy, retrospective diagnosis in the follow-up observation. The diagnosis of transudative pleural effusion is based on medical history such as CHF, kidney failure and cirrhosis and so on, normally with polyserositis. Examination and detection of blood albumin, BNP and renal function help in the diagnosis of transudative pleural effusion. Left ventricular systolic dysfunction on echocardiography and response to diuretic therapy support the diagnosis of CHF, and hypoproteinemia regularly induce to transudative pleural effusion. 
From each patient $10 \mathrm{ml}$ of pleural fluid were transferred to $15 \mathrm{ml}$ Eppendorf tubes. Following centrifugation at $4000 \mathrm{rpm}$ for $10 \mathrm{~min}$ at $4^{\circ} \mathrm{C}$ supernatants were dispensed into $1 \mathrm{ml}$ Eppendorf tubes and were refrigerated at $-80^{\circ} \mathrm{C}$ until to work-up for the survivin measurement.

In this study, Human Total Survivin Enzyme Immunometric Assay Kit (Shanghai Lengton Bioscience Co. LTD., China) was used. According the package insert of the kit the dynamic range of the assay was between 5 and $1000 \mathrm{pg} / \mathrm{ml}$. The sample will be doubling diluted if the content of surviving is above $1000 \mathrm{pg} / \mathrm{ml}$. All pleural effusion samples and regents were kept on bench until they reached to the room temperature. All the processes were carried out at room temperature according to instructions of the manufacturer.

\subsection{Statistical Analysis}

Patient demographics and disease characteristics were summarized using descriptive statistics. Sensitivity and specificity were calculated. All continuous data were expressed as mean and standard deviation, and categorical variables as frequency and percentage. Statistical mean difference between the groups was analyzed with Student t-test and in case of more than two groups with one-way ANOVA test. Kaplane-Meier was used in survival analysis and survival difference between groups was studied with the log-rank test. To analyze factors that effected survival, Cox regression test was used in which survivin level, age, sex, smoking, primary lung cancer and other than lung cancer were included as independent variables. Statistical significance was set at $\mathrm{p}$ value $<0.05$. SPSS version 21 package program has been used for statistical analysis.

\section{Results}

Our study was carried out with 65 patients [M/F: 44/21, age (27 - 97 years)], referred to the affiliated Hospital of Hangzhou Normal University, and diagnosed with MPE, TPE and transudative pleural effusion between March 2017 and September 2017. Distribution of the patients according to the diagnoses is shown in Table 1 and demographic characteristics in Table 2.

\subsection{Survivin Levels in Subjects}

Mean value of survivin in MPE, TPE and transudative pleural effusion were $320.50 \pm 228.24 \mathrm{pg} / \mathrm{ml}, 328.35 \pm 146.79 \mathrm{pg} / \mathrm{ml}$, and $318.87 \pm 208.39 \mathrm{pg} / \mathrm{ml}$ respectively. No statistically significant difference was found between the three groups ( $\mathrm{p}=0.989)$ (Figure 1$)$. When the patients were divided into two groups as malignant and non-malignant pleural effusion, there is no statistically significant difference was found between the two groups too $(320.50 \pm 228.24 \mathrm{pg} / \mathrm{ml}$ versus $324.76 \pm 169.15 \mathrm{pg} / \mathrm{ml}, \mathrm{p}=0.648$ ) (Figure 2).

In the group of MPE, mean levels of survivin according to tumor origins are reported on Table 1. Patients with MPE were divided into two groups as primary lung cancer and extra-pulmonary metastatic carcinomas. Mean levels of 
Table 2. Demographical features of patients.

\begin{tabular}{ccccc}
\hline & MPE (36) & TPE (18) & Transudative (11) & $\mathrm{p}$ \\
\hline Age & $70.72 \pm 14.12$ & $60.89 \pm 21.81$ & $70.63 \pm 15.96$ & 0.119 \\
Age (min-max) & $46-96$ & $27-90$ & $52-97$ & \\
Sex (F/M) & $13 / 23$ & $4 / 14$ & $4 / 7$ & 0.560 \\
Smoking (y/n) & $14 / 22$ & $7 / 11$ & $1 / 10$ & 0.102 \\
\hline
\end{tabular}

One-way ANOVA, $\mathrm{x}^{2}$ test, $\mathrm{p}<0.05$ is significant.

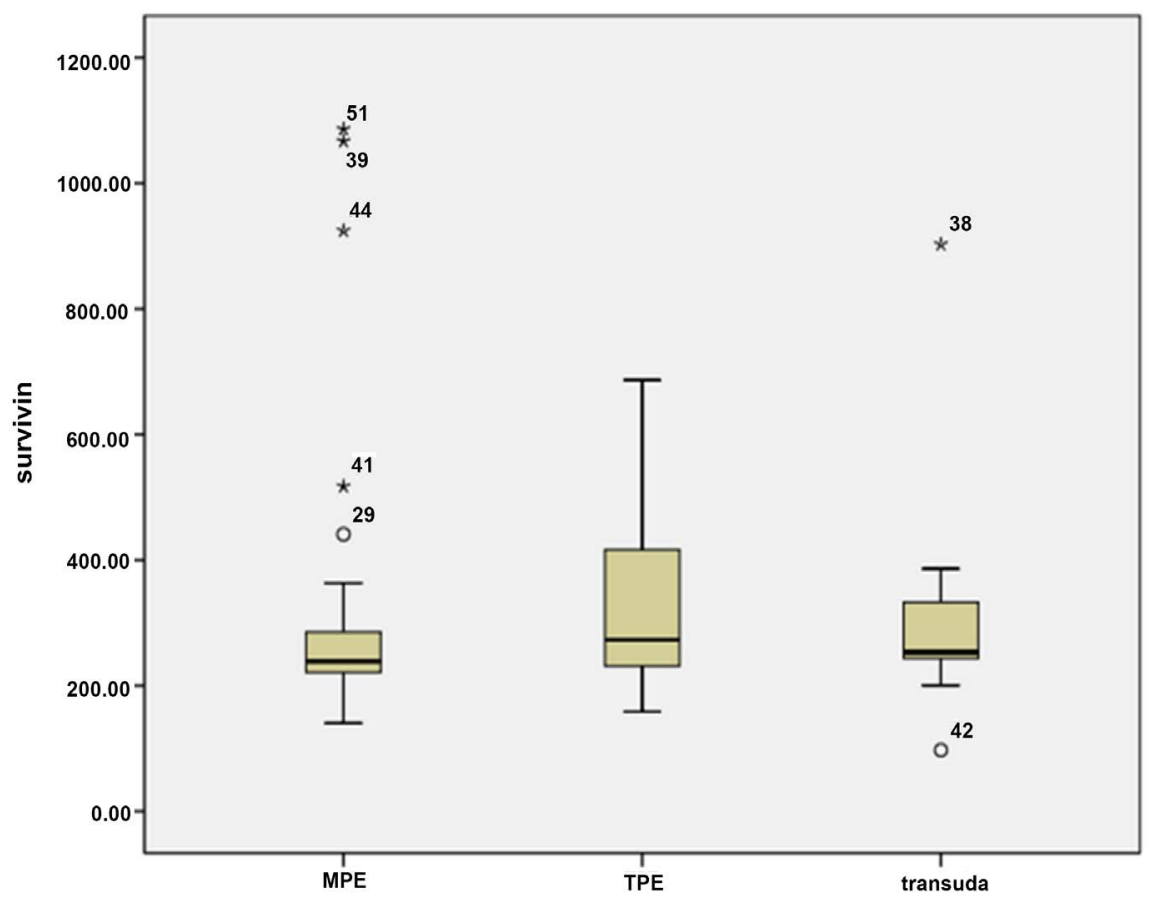

Figure 1. Mean value of survivin in MPE, TPE and transudative pleural effusion ( $\mathrm{p}=$ $0.989)$.

survivin were found as $238.66 \pm 48.19 \mathrm{pg} / \mathrm{ml}$ in primary lung carcinomas $(\mathrm{n}=$ 21) and $435.09 \pm 320.62 \mathrm{pg} / \mathrm{ml}$ in extra-pulmonary metastatic carcinomas ( $\mathrm{n}=$ 15). Statistically significant difference was found between the two groups according to survivin level $(\mathrm{p}=0.033)$. However no significant correlation was found in terms of age and sex (Figure 3 ).

\subsection{Discriminative Power of Survivin in MPE}

ROC curve was created to find sensitivity and specificity of survivin level in MPE vs. non-MPE group. Area under the ROC curve was 0.422. Considering cutoff value as $254.85 \mathrm{pg} / \mathrm{ml}$, sensitivity was found as $44.4 \%$ and specificity as $48.3 \%$. According to the results, survivin had no discriminative power in differentiating MPE and non-MPE (Figure 4).

The ROC curve has also been drawn for MPE and TPE, which were two significant etiological reasons for exudative effusions. Area under the ROC curve 


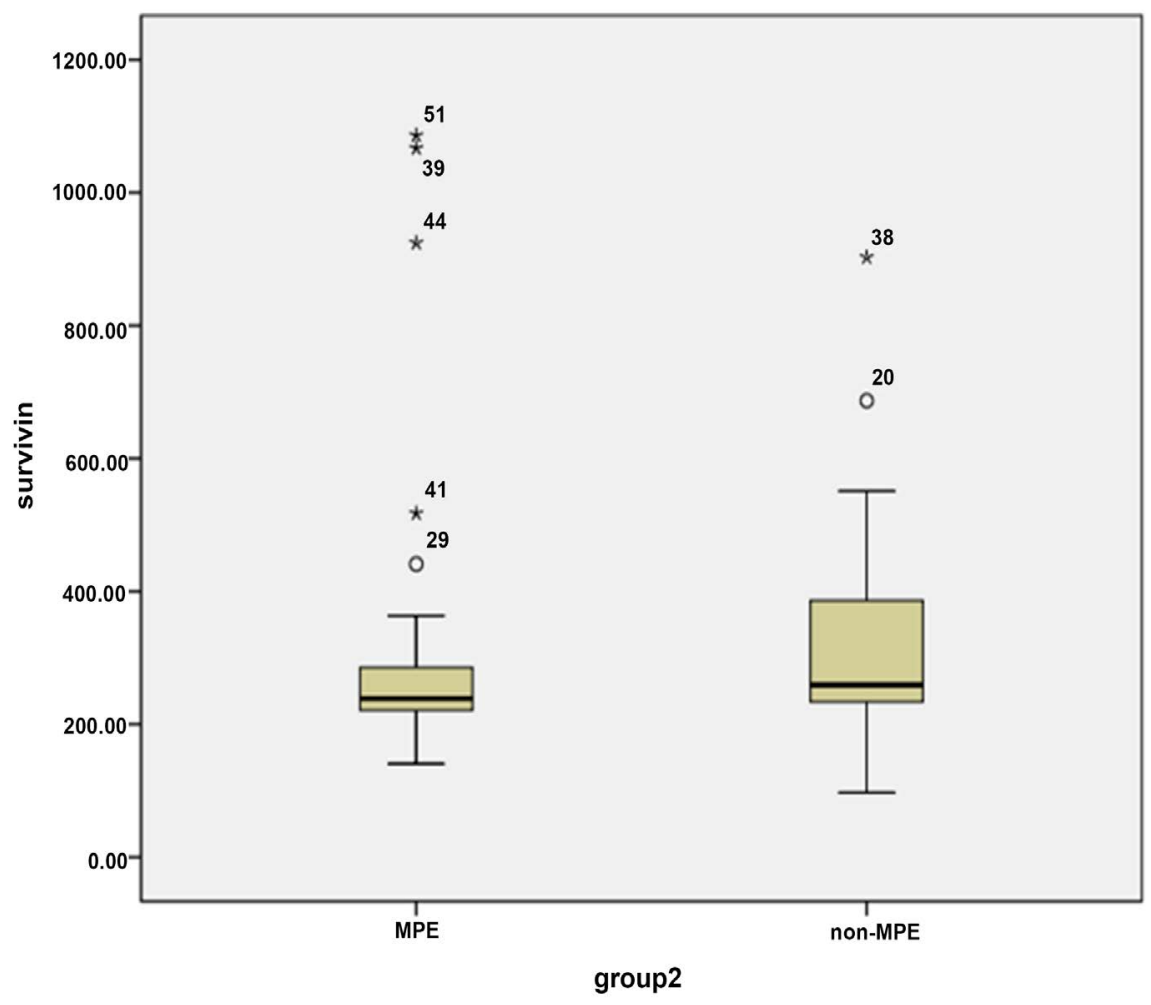

Figure 2. Comparisons of survivin levels between malignant and non-malignant effusions $(320.50 \pm 228.24 \mathrm{pg} / \mathrm{ml}$ versus $324.76 \pm 169.15 \mathrm{pg} / \mathrm{ml}, \mathrm{p}=0.648)$.

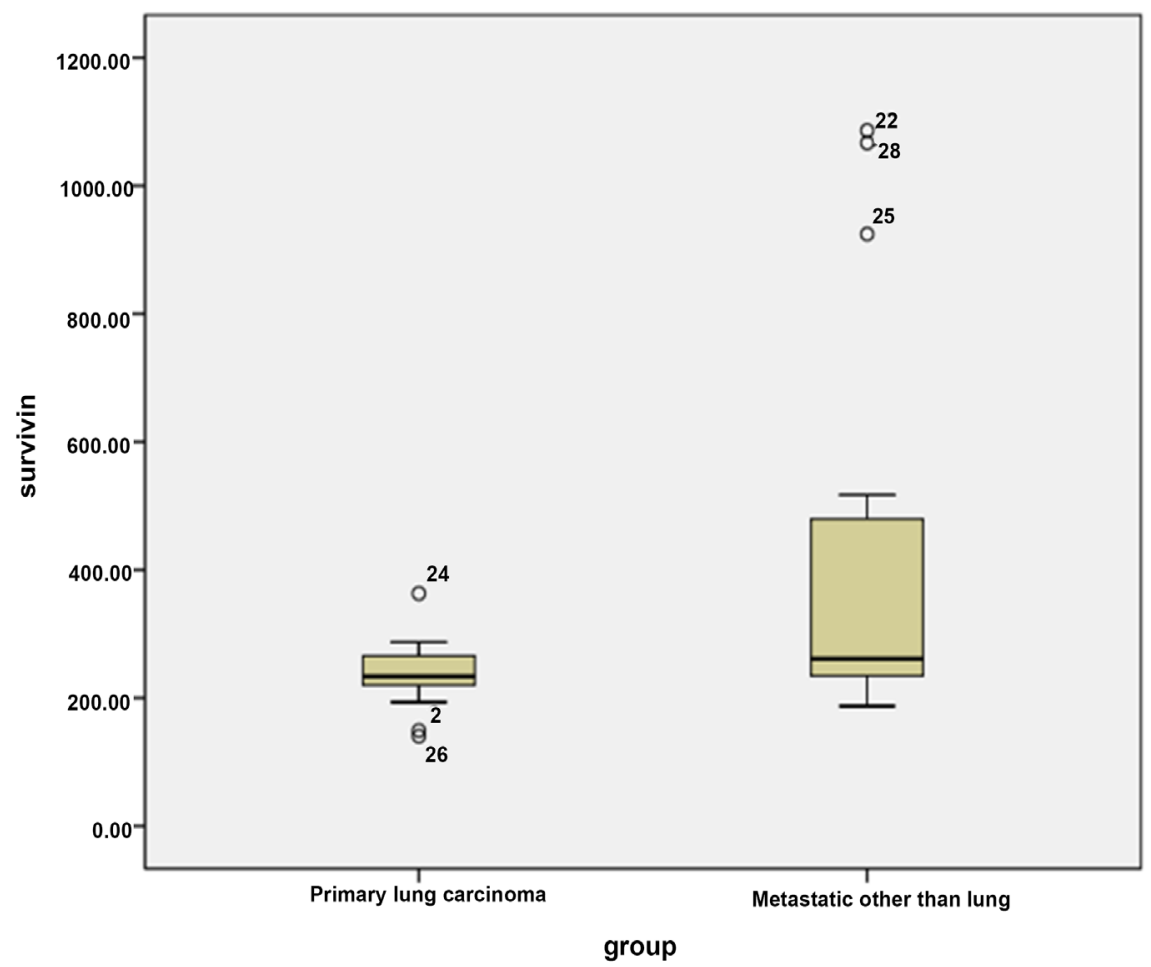

Figure 3. Comparisons of survivin levels between primary lungcarcinomas and extra-pulmonary metastatic carcinomas effusions $(238.66 \pm 48.19 \mathrm{pg} / \mathrm{ml}$ versus $435.09 \pm$ $320.62 \mathrm{pg} / \mathrm{ml}, \mathrm{p}=0.033)$. 


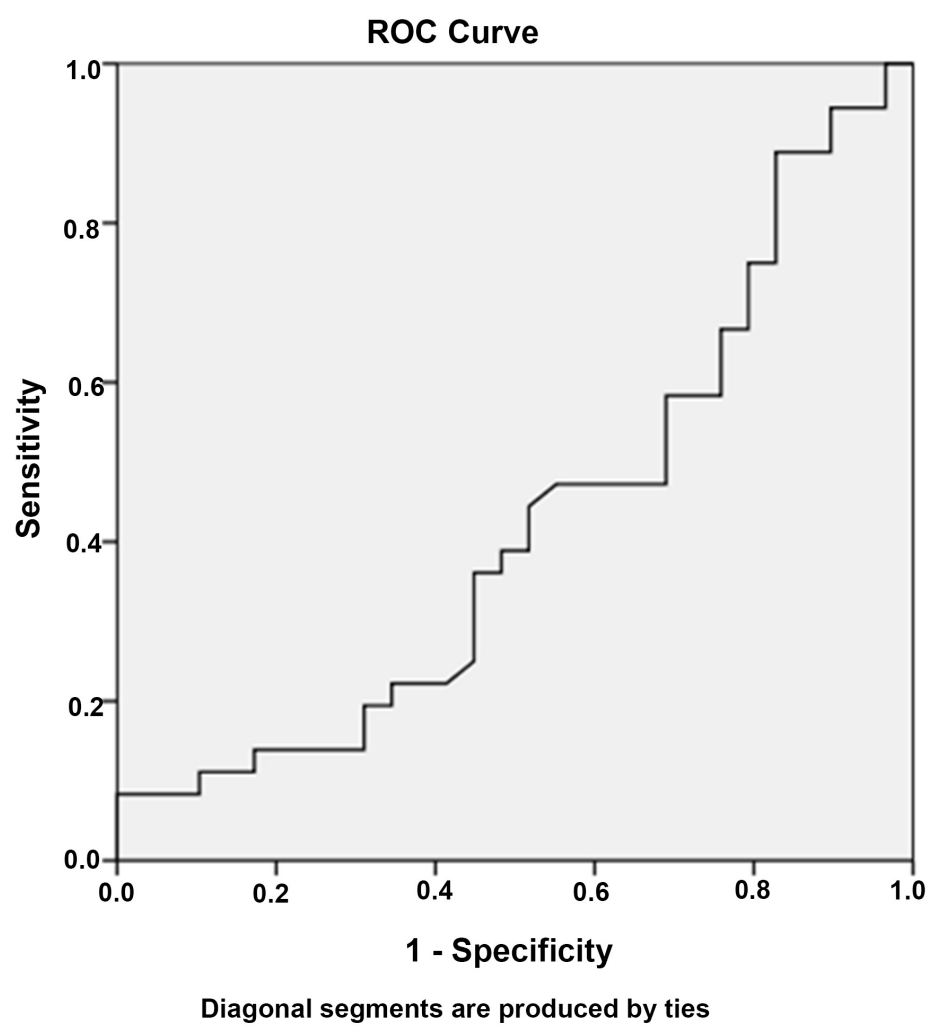

Figure 4. ROC analysis for survivin expression in MPE vs non-MPE group. The plot was constructed by computing the sensitivityvs. (1-specificity) for the different possible cutoff points of the survivin ELISA assay.

was 0.419 , for the cutoff value of $254.85 \mathrm{pg} / \mathrm{ml}$ sensitivity was $44.4 \%$ and specificity $55.6 \%$. According to the results, survivin had no discriminative power in differentiating exudative effusions of MPE and TPE all the same (Figure 5).

Similarly, when the ROC curve was drawn with MPE and transudative pleural effusion, area under the ROC curve was 0.428. Considering cutoff value as $254.85 \mathrm{pg} / \mathrm{ml} \mathrm{pg} / \mathrm{ml}$, sensitivity was found as $44.4 \%$ and specificity as $54.5 \%$. Same as above, survivin had no discriminative power in differentiating MPE and transudative pleural effusion.

However the dates indicated that metastatic other than lung cancer have more higher survivin expression than primary lung carcinoma in the pleural effusion. Statistically significant difference was found between metastatic other than lung $(435.09 \pm 320.62 \mathrm{pg} / \mathrm{ml})$ and primary lung carcinoma $(238.66 \pm 48.19 \mathrm{pg} / \mathrm{ml})$ groups according to survivin level. Area under the ROC curve was 0.686 , considering cutoff value as $266.59 \mathrm{pg} / \mathrm{ml}$, sensitivity was found as $60.0 \%$ and specificity as $71.6 \%$, and suggesting a moderate overall accuracy (Figure 6).

\subsection{Prognostic Value of Survivin in MPE}

Kaplane-Meier survival analysis was performed in the MPE group.

Survivin levels (the median value of surviving with $238.85 \mathrm{pg} / \mathrm{ml}$ as cutoff value $>238.85 \mathrm{pg} / \mathrm{ml}$ indicate a high survivin expression and $<238.85 \mathrm{pg} / \mathrm{ml} \mathrm{a}$ 


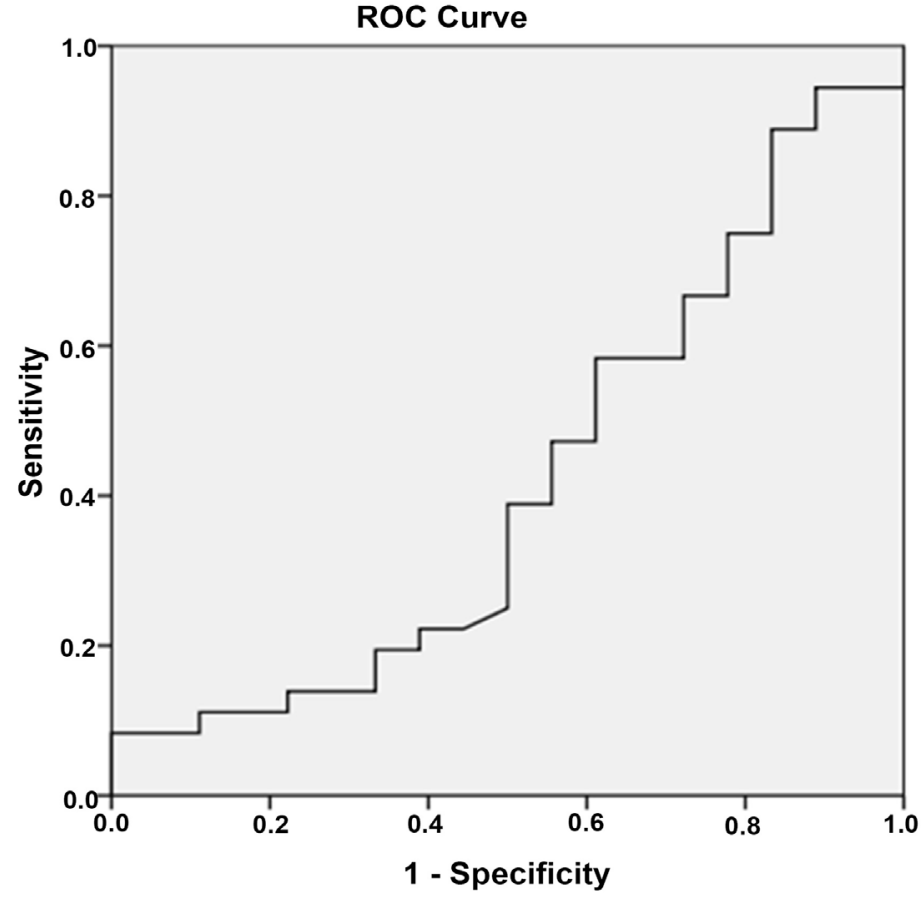

Diagonal segments are produced by ties

Figure 5. ROC analysis for survivin expression in MPE vs TPE group. The plot was constructed by computing the sensitivity vs. (1-specificity) for the different possible cutoff points of the survivin ELISA assay.

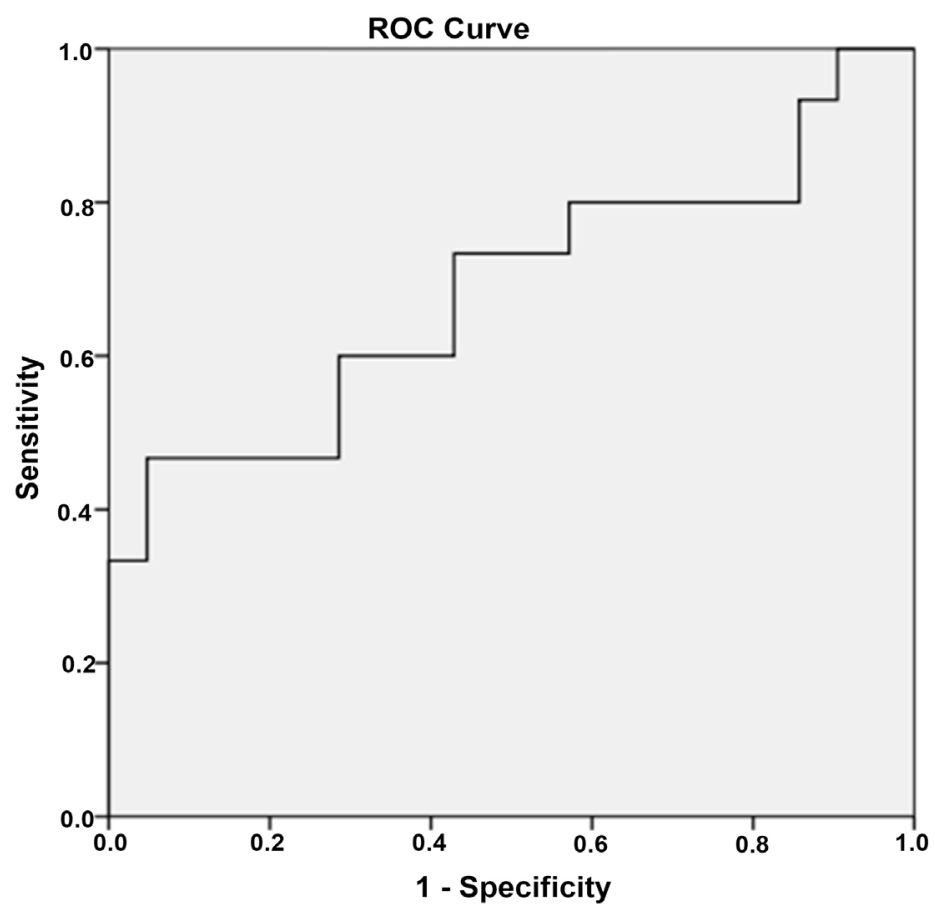

Figure 6. ROC analysis for survivin expression in Metastatic other than lung $(435.09 \pm 320.62 \mathrm{pg} / \mathrm{ml})$ vs. Primary lung carcinoma $(238.66 \pm 48.19$ $\mathrm{pg} / \mathrm{ml}, \mathrm{p}=0.004)$. Considering cutoff value as $266.59 \mathrm{pg} / \mathrm{ml}$, sensitivity was found as $60.0 \%$ and specificity as $71.6 \%$. 
low expression) can distinguish patients who had poor prognosis (median survival 96 days) and those who had good prognosis (median survival 206 days, $\mathrm{p}=$ 0.041). Elevated levels of surviving were related to reduced overall survival in Kaplane-Meier analysis (Figure 7, Table 3).

Cox regression analysis was carried out for significant factors influencing survival. Survivin level, age, sex, smoking, the group of primary lung cancer or other than lung cancer were included as independent factors. Survivin level, age, the group of primary lung cancer or not was retained as significant in backward elimination likelihood ratio test (Table 4).

\section{Discussion}

Survivin is a $16.5 \mathrm{kDa}$ protein that inhibits apoptosis, promotes proliferation, and has a crucial role in the development of cancer. Survivin is expressed in a vast majority of human cancers [14] and is one of the key factors conferring and maintaining resistance to apoptosis [15], and its over-expression correlates with poor outcome [16] [17] [18]. But conflicting results have been published in association between survivin levels in serum and the prognosis of cancer [19] [20] [21] [22]. Furthermore, studies about survivin expression in pleural effusions are limited [23] [24]. Wu and colleagues [25] have analyzed pleural effusion specimens for survivin expression using ELISA. They reported remarkable sensitivity

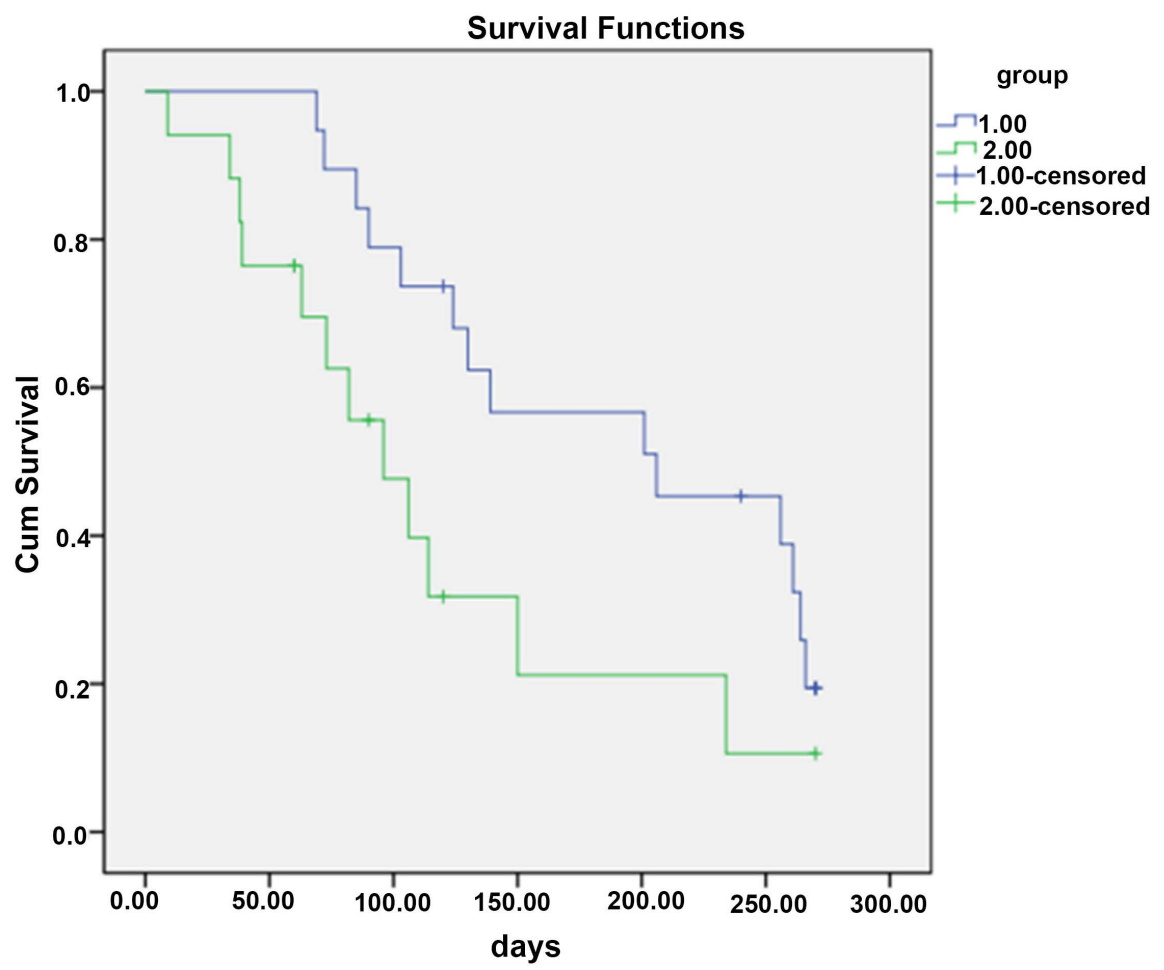

Figure 7. Kaplane-Meier survival curve showing the association between survivin expression and overall survival $(\mathrm{p}=0.041)$. Curve 1: low expression of survivn with Survivin levels $<238.85 \mathrm{pg} / \mathrm{ml}$; Curve 2: high expression of survivn with Survivin levels $>238.85$ $\mathrm{pg} / \mathrm{ml}$. 
Table 3. Test of equality of survival distributions for the different levels of group.

\begin{tabular}{|c|c|c|c|}
\hline \multicolumn{4}{|c|}{ Overall Comparisons } \\
\hline & Chi-Square & $\mathrm{df}$ & Sig. \\
\hline Log Rank (Mantel-Cox) & 4.172 & 1 & .041 \\
\hline
\end{tabular}

Table 4. Cox regression analysis data.

\begin{tabular}{ccccccc}
\hline & B & SE & Wald & df & Sig. & $\operatorname{Exp(B)}$ \\
\hline Age & 0.047 & 0.023 & 3.949 & 1 & 0.047 & 1.048 \\
Sex & -0.061 & 0.581 & 0.011 & 1 & 0.916 & 0.940 \\
Smoking & 0.115 & 0.824 & 0.019 & 1 & 0.889 & 1.121 \\
Survivin & 0.005 & 0.001 & 13.165 & 1 & 0.000 & 1.005 \\
Primarylungornot & -2.945 & 1.158 & 6.472 & 1 & 0.011 & 0.053 \\
\hline
\end{tabular}

and specificity with a cutoff value of $6.2 \mathrm{pg} / \mathrm{ml}$. Interestingly, more than half of the TPE patients expressed survivin in the same study. It is known that TPE is frequently diagnosed as the cause of exudative pleural effusion in Asia and in our country. Our study included 18 TPE diagnosed, compared with MPE, according to our results, survivin had no discriminative power in differentiating exudative effusions of MPE from TPE. ROC curves for MPE versus TPE were analyzed and for the cutoff value of $254.85 \mathrm{pg} / \mathrm{ml}$ sensitivity was $44.4 \%$ and specificity $55.6 \%$. Our results revealed that the sensitivity of survivin is low, which limits the clinical utility of survivin as a screening biomarker for MPE. Because in our country tuberculosis is endemic, discrimination between exudative effusions of MPE and TPE was very important and survivin had no discriminative power in such cases.

Interestingly, we were found that compared with primary lung carcinoma $(238.66 \pm 48.19 \mathrm{pg} / \mathrm{ml})$, Survivin levels were elevated in the group of metastatic other than lung $(435.09 \pm 320.62 \mathrm{pg} / \mathrm{ml}, \mathrm{p}=0.033)$. No association has been detected between surviving levels of pleural effusion and age, sex, smoking states to our findings. According to previous studies increased survivin levels of mRNA expression in pleural effusion were associated with poor survival [23] [26]. Similary, in our study, elevated levels of survivin was correlated with a reduced overall survival. Survivin levels can distinguish patients as a poor and good prognostic group.

In our study, survivin level was analyzed with ELISA technique. In the literature, survivin levels were studied with various methods such as mRNA with PCR, immune-blotting and ELISA. Analysis using various methods makes it difficult to compare the results.

\section{Conclusion}

In conclusion, the findings of this study suggest that survivin levels can be ele- 
vated both in inflammation and malignancies. It can be suggested that positive values of survivin might be misleading in the regions with a high prevalence of TPE like in our country and cannot be used as a safe diagnostic tool in differentiation between TPE and MPE. However, beside its questionable diagnostic role aside, survivin has a potential role as a promising prognostic marker for MPE.

\section{Conflicts of Interest}

The authors declare no conflicts of interest regarding the publication of this paper.

\section{References}

[1] Marel, M., Stastny, B., Melnova, L., et al. (1995) Diagnosis of Pleural Effusions: Experience with Clinical Studies, 1986 to 1990. Chest, 107, 1598-1603. https://doi.org/10.1378/chest.107.6.1598

[2] Heffner, J.E., Brown, L.K. and Barbieri, C.A. (1997) Diagnostic Value of Tests That Discriminate between Exudative and Transudative Pleural Effusions. Primary Study Investigators. Chest, 111, 970-980. https://doi.org/10.1378/chest.111.4.970

[3] Burrows, C.M., Mathews, W.C. and Colt, H.G. (2000) Predicting Survival in Patients with Recurrent Symptomatic Malignant Pleural Effusions: An Assessment of the Prognostic Values of Physiologic, Morphologic, and Quality of Life Measures of Extent of Disease. Chest, 117, 73-78. https://doi.org/10.1378/chest.117.1.73

[4] Morgensztern, D., Waqar, S., Subramanian, J., et al. (2012 ) Prognostic Impact of Malignant Pleural Effusion at Presentation in Patients with Metastatic Non-Small-Cell Lung Cancer. Journal of Thoracic Oncology, 7, 1485-1489.

[5] Rakha, E.A., Patil, S., Abdulla, K., et al. (2010) The Sensitivity of Cytologic Evaluation of Pleural Fluid in the Diagnosis of Malignant Mesothelioma. Diagnostic Cytopathology, 38, 874-879. https://doi.org/10.1002/dc.21303

[6] Brock, M.V., Hooker, C.M., Yung, R., et al. (2005) Can We Improve the Cytologic Examination of Malignant Pleural Effusions Using Molecular Analysis? Annals of Thoracic Surgery, 80, 1241-1247.

[7] Puzman, P., Terl, M. and Mukensnabl, P. (2006) Medical Video-Thoracoscopy in Diagnosis and Therapy of Pleural Effusions. Vnitřní Lékařství, 52, 321-327.

[8] Thomas, J.M. and Musani, A.I. (2013) Malignant Pleural Effusions: A Review. Clinics in Chest Medicine, 34, 459-471. https://doi.org/10.1016/j.ccm.2013.05.004

[9] Gu, Q., Hu, C. and Qu, J. (2013) Good Response of Malignant Pleural Effusion from Carcinoma of Unknown Primary Site to the Anti-Tuberculosis Therapy: A Case Report. International Journal of Clinical \& Experimental Pathology, 6, 973-977.

[10] Shin, S., Sung, B., Cho, Y., et al. (2001) An Anti-Apoptotic Protein Human Survivin Is a Direct Inhibitor of Caspase-3 and 7. Biochemistry, 40, 1117-1123. https://doi.org/10.1021/bi001603q

[11] Shinohara, E.T., Gonzalez, A., Massion, P.P., et al. (2005) Nuclear Surviving Predicts Recurrence and Poor Survival in Patients with Resected Non-Small Cell Lung Carcinoma. Cancer, 103, 1685-1692. https://doi.org/10.1002/cncr.20951

[12] Shintani, M., Sangawa, A., Yamao, N., et al. (2013) Immunohistochemical Expression of Nuclear and Cytoplasmic Survivin in Gastrointestinal Carcinoma. International Journal of Clinical \& Experimental Pathology, 6, 2919-2927.

[13] Warnecke-Eberz, U., Baldus, S.E., Bollschweiler, E., et al. (2008) Up-Regulation of 
Survivin mRNA Might Be a Marker for Non-Invasive Detection of Non-Small Cell Lung Cancer Rather Than for Prognosis. Anticancer Research, 28, 1525-1529.

[14] Li, F., Ambrosini, G., Chu, E.Y., et al. (1998) Control of Apoptosis and Mitotic Spindle Checkpoint by Surviving. Nature, 396, 580-584.

https://doi.org/10.1038/25141

[15] Yamamoto, T. and Tanigawa, N. (2001) The Role of Survivin as a New Target of Diagnosis and Treatment in Human Cancer. Medical Electron Microscopy, 34, 207-212. https://doi.org/10.1007/s007950100017

[16] Church, D.N. and Talbot, D.C. (2012) Survivin in Solid Tumors: Rationale for Development of Inhibitors. Current Oncology Reports, 14, 120-128. https://doi.org/10.1007/s11912-012-0215-2

[17] Nachmias, B., Ashhab, Y. and Ben-Yehuda, D. (2004) The Inhibitor of Apoptosis Protein Family (IAPs): An Emerging Therapeutic Target in Cancer. Seminars in Cancer Biology, 14, 231-243. https://doi.org/10.1016/j.semcancer.2004.04.002

[18] Altieri, D.C. (2003) Validating Survivin as a Cancer Therapeutic Target. Nature Reviews Cancer, 3, 46-54. https://doi.org/10.1038/nrc968

[19] Naumnik, W., Nilklinska, W., Ossolinska, M., et al. (2009) Serum Levels of HMGB1, Survivin, and VEGF in Patients with Advanced Non-Small Cell Lung Cancer during Chemotherapy. Folia Histochemica et Cytobiologica, 47, 703-709. https://doi.org/10.2478/v10042-009-0024-0

[20] Derin, D., Soydinc, H.O., Guney, N., et al. (2008) Serum Levels of Apoptosis Biomarkers, Survivin and TNF-Alpha in Non-Small Cell Lung Cancer. Lung Cancer, 59, 240-245. https://doi.org/10.1016/j.lungcan.2007.08.005

[21] Tian, P., Shen, Y., Wan, C., et al. (2014) Diagnostic Value of Survivin for Malignant Pleuraleffusion: A Clinical Study and Meta-Analysis. Postgraduate Medicine, 7, $5880-5887$.

[22] Li, J., Li, Z.N., Bao, Q.L., Ge, L.P., et al. (2012) Evaluation of Pleural Fluid Survivin and XIAP for the Diagnosis of Malignant Pleural Effusion. Tumor Biology, 33, 1803-1810. https://doi.org/10.1007/s13277-012-0439-7

[23] Lan, C.-C., Wu, Y.-K., Lee, C.-H., et al. (2010) Increased Survivin mRNA in Malignant Pleural Effusion Is Significantly Correlated with Survival. Japanese Journal of Clinic Oncology, 40, 234-240. https://doi.org/10.1093/jjco/hyp151

[24] Aĭtaliev, Sh.M., Alekseeva, L.A. and Zhanbyrbaev, N.B. (2012) The Utility of Survivin mRNA as a Diagnostic Biomarker in Lung Cancer with Malignant Pleural Effusion. Egyptian Journal of Chest Diseases and Tuberculosis, 61, 103-108. https://doi.org/10.1016/j.ejcdt.2012.10.029

[25] Wu, Y.K., Chen, K.T., Kuo, Y.B., et al. (2009) Quantitative Detection of Survivin in Malignant Pleural Effusion for the Diagnosis and Prognosis of Lung Cancer. Cancer Letters, 273, 331-335. https://doi.org/10.1016/j.canlet.2008.08.023

[26] Park, D.S., Hwang, K.E., Shim, H., et al. (2012) Elevated Survivin İs Associated with a Poor Response to Chemotherapy and Reduced Survival in Lung Cancer with Malignant Pleural Effusions. Clinical \& Experimental Metastasis, 29, 83-89. https://doi.org/10.1007/s10585-011-9431-7 